\title{
Professionalism in Science: Competence, Autonomy, and Service
}

\section{Hugh Desmond}

Published in: Science and Engineering Ethics

\begin{abstract}
Some of the most significant policy responses to cases of fraudulent and questionable conduct by scientists have been to strengthen professionalism among scientists, whether by codes of conduct, integrity boards, or mandatory research integrity training programs. Yet there has been little systematic discussion about what professionalism in scientific research should mean. In this paper I draw on the sociology of the professions and on data comparing codes of conduct in science to those in the professions, in order to examine what precisely the model of professionalism implies for scientific research. I argue that professionalism, more than any other single organizational logic, is appropriate for scientific research, and that codes of conduct for scientists should strengthen statements concerning scientific autonomy and competence, as well as the scientific service ideal.
\end{abstract}

Keywords: Research Integrity - Professionalism - Self-Regulation - Autonomy - Service

\section{Introduction}

In the past two decades, the realization has grown that the phenomenon of scientific misconduct is not limited to a few ill-intentioned scientists - the proverbial 'rotten apples' (Bouter 2015). It is now clear that there are also structural causes for this phenomenon: pressure 
to publish positive results, intense competition for research funds, a career progression that depends largely on metrics, the intertwining of commercial and scientific interests, and so on. Outright scientific misconduct is thus the tip of the iceberg and cannot be understood separately from 'questionable research practices' or QRPs (John et al. 2012) that lurk beneath the surface. The intentions involved in QRPs are not necessarily malevolent, but they give rise to incompetent or 'sloppy' science. This in turn is thought to be one of the causes of the so-called 'reproducibility crisis' (Baker 2016; Fanelli 2018; Open Science Collaboration 2015), when important studies across scientific disciplines have failed to replicate.

In response, significant changes in science policy have been implemented or are being discussed. One category of policy change aims to reform the incentive structure faced by individual scientists (Moher et al. 2018), while another aims to decrease QRPs through novel procedures (Munafò et al., 2017). A third front in this battle against misconduct and QRPs the one at issue in this paper - concerns the introduction of codes of conduct and guidelines on research integrity, which have proliferated in the past decades (Godecharle et al. 2013; Resnik, Rasmussen, et al. 2015). Concomitantly, research integrity training programs have been developed (Steneck 2013) and there are increasing calls for establishing integrity commissions to review allegations of misconduct (see e.g. Forsberg et al. 2018).

Some have seen this latter front as evidence of a larger trend towards the "professionalization" of scientific research (Shamoo and Resnik 2015, p. 4). In this view, the introduction of codes of conduct (and the accompanying changes) is merely the latest step in science's transition away from being the largely amateur activity it was in the $19^{\text {th }}$ century (Shapin 2008). Viewing the trend as nascent professionalization also has a normative implication: the response to crises in scientific misconduct and/or reproducibility should be to 
strengthen the professional self-regulatory capacity of the scientific community (see e.g. Taylor 2009). ${ }^{1}$

However, what precisely do 'professionalization' and 'professionalism' mean? Can scientific research be considered a 'profession'?2 Except for Robert Merton's oft-cited ideas on the 'ethos of science' (Merton 1942, 1973), the sociology of the professions (esp. Abbott 1988; Freidson 2001; Larson 1977; Wilensky 1964) has, by and large, been neglected in the field of research integrity and methodology. Consequently, the notion of 'profession' remains more or less undefined in this field. Nonetheless, as I will argue later, this is an important issue because the categorizing of scientific research as a profession or not has significant implications for the ethical questions at the core of scientific research. For instance, it impacts how we think about the values underlying scientific research, or about the responsibility of individual scientists.

There are also significant implications for how codes of conduct or policy documents on research integrity should be drawn up. These documents are position statements on what the most important values underlying research are, what the best research practices are, and what behaviors count as misconduct. Yet these documents have hitherto often been shaped by exigencies (i.e., high-profile cases of misconduct, see e.g. Price 2013, Nature 2018, German Data Forum 2011, p. 678). There is little academic literature on how such policy documents should be drawn up, beyond perhaps discussions of the definition of misconduct (Bornmann 2013; Resnik, Neal, et al. 2015; Resnik and Stewart 2012; Salwén 2015). This means that fundamental questions concerning the values and responsibilities of scientists are not fully addressed.

\footnotetext{
${ }^{1}$ Note that some sociologists have argued, by contrast, that science is undergoing a 'de-professionalization' (e.g. Dickel 2016) or hybridization (e.g. Carvalho and Santiago 2010), paralleling the changes in other professions (Noordegraaf 2015). These apparently opposing views on the social evolution of science will be discussed later in section 8.

${ }^{2}$ Note that in this paper, 'scientific research' will be understood to include humanities research. This usage has antecedents in the German/Dutch words Wissenschaft/wetenschap, but the main reason for adopting this usage is that most, if not all, codes of conduct for scientists and the issues treated therein (e.g., plagiarism, respect for colleagues, etc.) are intended to be applicable to humanities scholars also.
} 
This paper will propose that the logic of professionalism is appropriate for scientific research and will explore the implications for codes of conduct and policy documents on research integrity. The paper thus has a double purpose: (1) to explain what 'professions' and 'professionalism' (the first two sections) are in order to outline why professionalism is applicable to scientific research (the following two sections), and (2) to apply this framework to existing codes of conduct and policy documents, and to show how these, as currently formulated, fall short of professionalism (the final two sections). I will also strengthen the case by comparing scientists' codes of conduct with codes of conduct for physicians and lawyers these occupations are chosen because medicine and law are often taken to be exemplars of professional occupations (see e.g. Elliott 2013; Freidson 1970).

The upshot is that, if professionalism is taken to be a model, the codes of conduct should then be amended in (at least) two ways: (1) it should be possible to hold individual scientists accountable for incompetent research, even if it was unintentional, and (2) the values underlying research integrity should include 'the disinterested search for truth.'

\section{Defining the Professions}

In the broad, non-technical sense of the term, a 'professional' refers to someone who earns a living from an activity (as opposed to an amateur or hobbyist). However, more relevant for this paper is the narrower sense of the term, where professions refer to certain types of knowledge-based occupations, with law and medicine being the paradigmatic examples.

In this narrow sense, professions are often thought of as prestigious, client-focused, and highly paid. However, from a broader sociological perspective, these properties are incidental rather than defining characteristics of a profession. Eliot Freidson lists the elements that define the ideal type of a professional occupation: 
1. A body of knowledge and skill which is officially recognized as one based on abstract concepts and theories and requiring the exercise of considerable discretion;

2. An occupationally controlled division of labor [into different specializations];

3. An occupationally controlled labor market requiring credentials for entry and career mobility;

4. An occupationally controlled training program which produces those credentials, schooling that is associated with 'higher learning', segregated from the ordinary labor market and provides opportunities for the development of new knowledge;

5. An ideology serving some transcendent value and asserting greater devotion to doing good work than to economic reward (my emphasis, Freidson 2001, p. 180; emphases mine).

In this understanding, a profession is defined by five elements, which can be further grouped into three areas: individual autonomy (criterion 1), collective autonomy (criteria 2-4), and the service ideal (criterion 5). This way of grouping the elements together around autonomy and the service ideal is present in other prominent analyses of the professions (Abbott 1988; Macdonald 1995; Wilensky 1964). ${ }^{3}$

These elements - individual autonomy, collective autonomy, and the service ideal follow from the type of knowledge underlying the professional activity. ${ }^{4}$ First, individual autonomy follows when the occupational activity is sufficiently complex, involving the application of abstract theoretical knowledge to particular situations. Moreover, it must involve individual discretion; when technological innovation allows an activity to be made routine, this leads to what Andrew Abbott terms 'commodified expertise' (Abbott 1988). The latter refers

\footnotetext{
${ }^{3}$ Besides autonomy and ideals, professionalism can also be analyzed in terms of power. Thus the service ideals of the professions have long been accused of being ideals in name only, and in reality mere means to increase the wealth and power of the professional communities (Larson 1977).

${ }^{4}$ In fact, some have argued that the abstract character of the knowledge is the most defining feature of the professions (see e.g. Abbott 1988, p. 8, or Brante 2011).
} 
to the standardization of the activity, whereby the circumstances under which a specific task should be carried out can be specified in advance. In such cases it is not necessary that individual practitioners exercise their discretion; this is likely to even be undesirable, since adhering to standardized rules would minimize the risk of error.

For instance, the diagnosis established by an individual physician is ultimately shaped by individual discretion. There may be guidelines and rules for diagnosis, but in contrast, say, to an employee in a factory assembly line, these guidelines do not determine the service or the labor. One may attempt to make guidelines for diagnosis as complete as possible, but the importance of individual discretion is unavoidable due to the complexity of factors involved in a correct diagnosis, and to the ever-changing state of medical knowledge. If medical knowledge should ever advance to such a state as to make individual discretion unnecessary, then physicians would cease to be professionals.

Second, collective autonomy follows for closely related reasons, where the community of practitioners (perhaps via representation in a governing body) decide what tasks and specialized activities the members of the community will focus on, who can receive licenses to exercise the professional activity, and how they will be trained. Such decisions can only be made with an in-depth knowledge of the state of the art - and hence only by the practitioners themselves. In this way, the quality of professionals' knowledge, and ultimately the quality of their service, is ensured (Freidson 2001).

Third, since the danger always exists of such autonomy being used for mere self-serving purposes, in the traditional model of the professions (see also Wilensky 1964), autonomy is counterbalanced by a strong professional deontology or service ideal. This deontology means performing the professional service according to certain standards of competence, regardless of whether the client is able to distinguish between a competent and an incompetent service (Davis 1991). It is also connected with values or ideals, such as 'care' for physicians or 'justice' for 
lawyers. The deontology is strengthened by numerous practical measures: strictly regulated training procedures for aspiring professionals, a code of conduct, and a board of ethics to examine alleged infractions of the code. Such a deontology based on the service ideal would not be necessary if individual discretion were not crucial for successfully carrying out the professional activity.

Finally, by emphasizing the service ideal, a formal code of conduct is often associated with ideal-typical professions. Some of the aims of a code of conduct include: "to eliminate the unqualified and unscrupulous, (...) to reduce internal competition, and (...) to protect clients and emphasize the service ideal" (Wilensky 1964, p. 145). However, at a more fundamental level all these aims follow from enhancing the service ideal: adhering to the service ideal implies that one should provide a competent service, which in turn implies keeping abreast of developments in the field to maintain competence, as well as not prioritizing monetary gain, since this leads to competing with other professionals for clients, and thus potentially to compromising on the quality of the service.

\section{The Three Logics}

Interpreting the ideal-type of a professional occupation as a demarcation between professional and non-professional occupations leads to a host of problems. Occupations such as engineering, teaching, or nursing, for example, claim professional status but do not readily exhibit the collective autonomy of the traditional model of the professions. ${ }^{5}$ Conversely, there are occupations that cannot readily be deemed 'professions' and yet exhibit characteristics of professions: labor unions have codes of conduct, as do even criminal associations (see discussion in Brante, 2011). Moreover, viewed from historical time scales, occupations undergo significant changes, and even in the past decades established professions such as law and

\footnotetext{
${ }^{5}$ For a discussion of the role of codes of conduct in the engineering profession, see M. Davis 1991.
} 
medicine have changed significantly in many major OECD countries, with increasing levels of external control through reforms such as New Public Management (see Carvalho \& Correia, 2018).

An alternative is to interpret the ideal-type as the social attributes associated with an organizational logic (Freidson 2001), a method of "organizing and controlling the circumstances [of work]" (Freidson 2001, p. 179). Freidson contrasts the "logic of professionalism" with two alternative logics: the free market (going back to Adam Smith: Smith, 1776/2008) and a centralized bureaucracy (going back to Weber's rational-legal bureaucracy: Weber 1922/1978, and Marx’s command economy: Marx \& Engels 1848/2018).

[Figure 1 here]

The key differentiating factor between each logic lies in who controls what work the laborers or practitioners carry out, or in other words, which party is deemed to be the autonomous one. In a market, consumers or clients ultimately decide what work is carried out: the practitioners conform to the wishes of consumers or clients. In a bureaucracy, managers or administrators decide. In the third logic, professionalism, the community of practitioners is organized such that the practitioners themselves decide what work is carried out - not consumers, or managers. This is also known as self-regulation. ${ }^{6}$ The rationale or logic underlying the self-regulation of professionalism is that consumers and managers lack the specialized knowledge necessary to evaluate the tasks being carried out. This means that professionalism can be justified only when the knowledge necessary for a certain kind of task is solely obtainable with much effort, and so goes far beyond the common or daily knowledge

\footnotetext{
6 "Professionalism is a set of institutions which permit the members of an occupation to make a living while controlling their own work" (Freidson, 2001, p. 17).
} 
possessed by all adults in society. This explains why individual discretion in professional work has such a central role (see previous section).

It would be wrong to think that professionalism is 'better,' in some unqualified sense, than the other logics. Which logic is appropriate depends on the nature of the knowledge required for doing the work. To this end, Freidson (2001, pp. 17ff) distinguishes between everyday knowledge (the type possessed by all functioning adults), practical knowledge (the conscious or tacit know-how gained on the job), and formal knowledge (the knowledge that can be organized into theories and abstract concepts). Activities based on the first lend themselves to a market organization, those based on the second lend themselves to a bureaucratic organization while activities based on the third lend themselves to professional organization (Freidson 2001, p. 60). So, the nature of the knowledge underlying the work dictates what organizational logic is appropriate.

Despite the fact that organizational logics can be appropriate to varying extents for a given type of work, the type of work does not entirely determine which organizational logic becomes dominant. There can be competition between rival logics or ideologies, and over time one logic can come to dominate an occupation at the expense of others. This is why organizational logics are also to be understood as ideologies (Freidson 2001, p. 105): they constitute sets of values and ideas that justify the social structures typically associated with professions (or markets or bureaucracies).

Many exemplary professions themselves have been the battleground of ideologies in the past few decades. Whereas Harold Wilensky in 1964 was able to write that "bureaucracy may enfeeble the service ideal...[and] a client orientation undermines colleague control and professional norms" (Wilensky 1964, p. 137), today many professions have gone through exactly such fundamental changes, with increasing bureaucratization (i.e., managerial control) of professional activities, and an increased role being given to market regulation (as opposed to 
self-regulation). These changes started in the 1970s with the advent of New Public Management (Boyce 2008; Carvalho and Correia 2018), and have included removing barriers to competition between professionals, ${ }^{7}$ more accountability towards clients, allowing client demand to organize work, performance evaluations, and external audits. While some have labeled this a process of 'de-professionalization' (Clark 2005), others have argued that it has led to a new 'hybrid' professional model (Carvalho 2014; Kuhlmann et al. 2013; Noordegraaf 2015), where the logics of professionalism and bureaucracy are combined (for an overview, see Carvalho et al. 2018).

\section{Science, University Teaching, and the Professions}

Before moving to examine how the logic of professionalism is appropriate for scientific research, it is important to first note how scientific research today is intertwined with both university teaching and with professional practice (in domains such as medicine, engineering, law, dentistry, architecture, etc.). In this section some of the core elements in this complex interplay are identified.

While research is viewed today as one of the core missions of academics, this was not always the case. For most of the history of universities, the main service offered by university professors was teaching (Enders 2007). Scientific research, by contrast, was just as likely to be carried out by clergymen, physicians, surgeons, or by the independently wealthy. Only in the $19^{\text {th }}$ century, and especially after 1945 , as states increasingly recognized the commercial and military importance of science, were growing numbers of researchers given salaries to enable them to dedicate themselves full-time to scientific research (Shapin 2008). Nonetheless,

\footnotetext{
${ }^{7}$ Professionals may, for instance, be required to carry a license to carry out certain activities; the license thus serves not just to ensure a certain standard of quality, but also to limit competition. A code of ethics, in maintaining a focus on a service ideal, also serves to weaken consumer-focused competition between professionals (Abbott 1988; Wilensky 1964).
} 
groundbreaking research was carried out by non-salaried researchers well into the $19^{\text {th }}$ and $20^{\text {th }}$ centuries: Charles Darwin was independently wealthy; Gregor Mendel, one of the founders of genetics, was a monk; Albert Einstein was working as a patent clerk when he outlined the special theory of relativity (along with several other groundbreaking advances).

Moreover, while scientific research has, until relatively recently, been a largely amateur activity (discussed in Shapin 2008, pp. $34-46^{8}$ ), university teaching is one of the oldest established professions, and together with law, the clergy, and medicine, is included among the original 'status professions' (P. Elliott 2013).

In what way is university teaching shaped by the logic of professionalism? For one, its services are based on an established body of knowledge, and university teaching requires a large amount of individual discretion in organizing syllabi and classes. Some of its social attributes are also typical of a profession (see earlier definition of the ideal-type of a profession). For instance, there is considerable collective autonomy in how certain specializations (most of the humanities, and many fundamental sciences as well) are maintained, even though there may be little to no actual market demand for them, or even if they may seem less 'productive' compared to other specializations (e.g. in terms of number of doctorates, external funding, or number of publications; see Sabharwal 2013). In this way, professional self-regulation in academia does not just buffer the market goals of increasing competition and reducing cost, it can also buffer the managerial goals of efficiency and productivity.

However, university teaching is unique among the professions, in the following three respects. First, university professors function as the 'custodians of knowledge' and lead many of the training programs for the professions. This was historically the case in the medieval university (for law, medicine, and clergy), and in modern history the trend for professionals to receive their basic training at university has only strengthened, with many new professions

\footnotetext{
${ }^{8}$ Although note that Shapin does not use the term 'profession' in the technical sense defined above.
} 
having dedicated faculties (dentistry, civil engineering, etc.). For this reason academics have variously been dubbed the "producers of producers" (Larson 1977), the "profession that educates the other professions" (Perkin 1969), or simply the "meta-profession" (Carvalho 2017).

Second, university teaching has also been an area where conflicts over authority or jurisdiction between professions are fought out. New professions can appear and claim jurisdiction over a new activity, 'invading' the jurisdiction of an old profession. One of the key ways to gain supremacy over some activity is by gaining an upper hand in what is taught to students - and this is where it becomes difficult to distinguish between university teaching and scientific research. For instance, in the late $19^{\text {th }}$ century, psychiatrists competed with spiritualism practitioners for jurisdiction over mental problems (Abbott 1988 p. 29), and psychiatrists' claim to scientific knowledge - and thus superior scientific research - was crucial in this respect. For this reason, Abbott argues that one of the most important functions of scientific knowledge in a profession is to legitimize the profession's jurisdiction:

Academic knowledge legitimizes professional work by clarifying its foundations and tracing them to major cultural values. In most modern professions, these have been the values of rationality, logic, and science (Abbott 1988 p. 54).

Even when two professions have already been institutionalized at a university, competition can occur. Abbott gives the example of psychiatrists struggling with lawyers in the 1920s, arguing about who - lawyers or psychiatrists - should decide issues of personal responsibility in court (Abbott 1988, p. 55). The ensuing theoretical debate about the nature of personal responsibility can thus be viewed, according to Abbott, as actually a competition over jurisdiction (the psychiatrists lost).

In sum, codifying professional know-how in a body of scientific knowledge that can be taught at university is a way for an occupation to gain dominance. However - and this is the third aspect - this codifying is also what ensures the long-term competence of a profession. 
Making professional know-how amenable to teaching entails a high degree of abstraction, and this abstraction has several advantages. It allows for more efficient instruction, so that the professionals can learn basic principles that are applicable in a wide range of circumstances. It also allows a subgroup of professionals to dedicate themselves to discovering new ways to deal with professional problems - or in other words, to engage in a type of scientific research. Physician-researchers and lawyer-researchers, who retain both an academic affiliation as well as a professional practice, are a case in point. Finally, this increased competence allows for long-term dominance:

... only a knowledge system governed by abstractions can redefine its problems and tasks, defend them from interlopers, and seize new problems - as medicine has recently seized alcoholism, mental illness, hyperactivity in children, obesity, and numerous other things. Abstraction enables survival in the competitive system of professions (Abbott 1988, p. 8).

In sum, both research and teaching in universities can be offshoots of professions, either for improving professional knowledge and instructing the next generation of professionals, or as a means to dominate other professions. Nonetheless, research is an activity distinct from both university teaching as well as non-academic professions: in what way the logic of professionalism is appropriate for research is the topic of the next section.

\section{Is Professionalism Appropriate for Scientific Research?}

Is scientific research a profession? Some sociologists deny this, pointing to the absence of clients as a reason for not categorizing scientific research as a profession (Stichweh 1997; Wilensky 1964, p. 41). Others have answered in the affirmative, noting the relationship of trust between science and the wider society, and scientists' 'fiduciary responsibility' in the "preservation, developmental, and utilization of (...) significant and valid knowledge" (Parsons 1978, p. 30). 
Since this disagreement could potentially degenerate into a purely verbal one, it is more fruitful to ask to what extent the logic of professionalism is applicable to scientific research. In this section, I argue that the logic of professionalism - and not the logics of bureaucracy and of the markets - is a logic primarily appropriate for scientific research. Of course, in reality a mix of logics may be more optimal than pure professionalism, but this is a separate question (see final section). The argument here concerns how, given basic considerations about the nature of research, individual discretion plays an ineliminable role in research. Hence, if one were to choose only one organizational logic from the three possibilities, professionalism would be the most appropriate one.

Recall how the logic of professionalism (in the Freidsonian sense) is appropriate when the work or occupation involves applying knowledge that is complex enough to require the exertion of individual discretion. This prevents the activity from being turned into a rule-based activity with a controllable outcome (or a client-driven activity where the outcome can be shaped according to the wishes of the client $^{9}$ ). In this way, the logic of professionalism depends in the first instance on the fundamental relation between the activity and the knowledge ${ }^{10}$ that underlies it. What does this relation look like for the activity of scientific research?

I will limit the discussion to two elements: the role of novelty, and the absence of an exceptionless set of rules when carrying out scientific research. First, through its very activity, scientific research can undermine the methodological rules and knowledge upon which it was based. It is in this context that the Kuhnian distinction between 'normal' and 'revolutionary' science can be illustrative (Kuhn 1962). Normal science is incremental research, applying established concepts and methodologies to well-defined problems, and proposing solutions. By

\footnotetext{
${ }^{9}$ Since the market-based logic is, in this sense, eminently less applicable to the activity of scientific research, the rest of the discussion will focus on the contrast between the logics of professionalism and bureaucracy.

${ }^{10}$ Note that I am using the term 'knowledge' in a sociological rather than an epistemological sense: a hypothesis or theory constitutes established knowledge when it is taken by the scientific community to be true (even if it may actually be false).
} 
contrast, revolutionary science concerns the rethinking of fundamental concepts and methodology, and often involves fundamentally redefining the problems that need to be solved. The Kuhnian view may very well be flawed in some respects (see e.g. Toulmin 1970); nonetheless, one need not subscribe to all aspects of the Kuhnian view to agree that not all scientific research can be turned into a rule-based activity. This innovative character of scientific research is lacking in other professional activities: medical or legal practice do not aim at upending established knowledge in the way scientific research (sometimes) does. This suggests an even greater role for individual discretion in research contexts where established rules (or Kuhnian paradigms) may be lacking.

Let us focus on incremental rule-based ('normal') science for a moment: it would be a mistake to think of this as an algorithmic activity with no role for individual discretion. Consider two classic reasoning schemes: induction and confirmation, and falsification. In the first the scientist inductively generalizes from observations, and then seeks to confirm that generalization through further observation. In the second, the scientist seeks observations that negate established knowledge (Popper 2005). However, neither scheme can be followed algorithmically. In some circumstances, scientists will reject a well-confirmed theory in favor of a less-confirmed one, while in other circumstances, they will continue to accept a hypothesis that has been apparently falsified. An example of the former is how the Ptolemaic system, despite a very significant degree of confirmation, was still abandoned for the Copernican system (Lakatos 1978). An example of the latter is how Darwin's theory of evolution by natural selection immediately seemed to have been falsified because the theory seemed to imply that novel phenotypes could not spread in populations (Jenkins' 1867 'swamping argument': see Bulmer 2004). Only later (in the 1920s) did it turn out that this discrepancy was due to a mistaken model of inheritance. 
While a few philosophers have taken such phenomena as supporting the view that science is an anarchic activity (Feyerabend 1975), most in fact distinguish between good and bad methodology (for an overview, see Andersen and Hepburn 2016). There is such a thing as scientific competence (knowing good methodologies from bad), even though individual discretion (judging how to apply a good methodology) is necessary as well. Falsification may not always be applicable; nonetheless, trying to formulate falsifiable hypotheses is, in general, a good methodology.

Distinctions between good and bad methodology also fulfill important sociological functions of 'boundary work' (Gieryn 1983), where scientific domains are demarcated from non-scientific ones. Such boundary work is structurally similar to the creation of (Abbottian) jurisdictions:

Demarcation is routinely accomplished in practical, everyday settings: education administrators set up curricula that include chemistry but exclude alchemy; the National Science Foundation adopts standards to assure that some physicists but no psychics get funded... (Gieryn 1983, p. 781).

Moreover, such boundary work can be influenced by social processes that are relatively independent of purely epistemological considerations, for instance power struggles for positions of trust or for political influence (Collins and Evans 2002).

All this illustrates how schemes of scientific reasoning are not the type of rules that would allow for the routinization of, and the expunging of individual discretion in scientific research, even when it concerns the most normal of 'normal science'. In this respect, a pure logic of bureaucracy or of markets is not applicable to scientific research; the logic of professionalism is the logic primarily appropriate for scientific research. While this conclusion in itself may be relatively uncontroversial, it has far-ranging implications. The following two sections will look at two specific aspects of the logic of professionalism - the service ideal, and the extent of responsibility. The first guides and informs individual discretion; the second refers 
to how an individual is responsible for an action when the action is determined by individual discretion.

\section{The Service Ideal in Scientists' Codes of Conduct}

At this point in the paper we will now make a more policy-oriented turn and examine how current codes of conduct for scientists hold up to the logic of professionalism. Two notions in particular will be examined: the service ideal and autonomy (together with the closely related notion of competence). For each notion, codes of conduct in science will be contrasted with codes of conduct in medicine and law, two exemplary professions (P. Elliott 2013; Freidson 1970).

\section{The Service Ideal in Medicine and Law}

First, consider how the American Medical Association's (AMA) code of ethics describes its ethical statements as developed "primarily for the benefit of the patient," and states in the very first principle:

A physician shall be dedicated to providing competent medical care, with compassion and respect for human dignity and rights (AMA 2001).

Of course, physicians may in fact fail to live up to this ideal of care in varying degrees. Nonetheless, the prominence of the ideal in the code of ethics indicates the weight placed on the ideal by the professional community of physicians. The duty of care for the patient is to be held as the ideal over and above the physician's personal gain, and in principle is even to be distinguished from the patient's own preferences (which may not be aligned with the ideal of care).

In the Model Rules of Professional Conduct (drawn up by the American Bar Association), the first responsibility of the lawyer is defined thus: 
A lawyer, as a member of the legal profession, is a representative of clients, an officer of the legal system and a public citizen having special responsibility for the quality of justice (ABA 2018; Preamble and Scope; my emphasis).

In this way it can be seen how, both in the legal and medical professions, the service ideal is defined in terms of quasi-Platonic ideals of care and justice.

Note that such service ideals are not only defined in terms of abstract ideals such as care and justice. The abstractness of such ideals comes at the expense of giving concrete guidance, and a professional service ideal is typically supported by a number of auxiliary norms governing client relations and colleague relations (Wilensky 1964, p. 140): for instance, avoiding emotional involvement with the client, or giving equal service to all clients, or deferring, where appropriate, to other specializations or other more competent colleagues (see for instance IV and $\mathrm{V}$ in AMA 2001).

\section{The Traditional Scientific Service Ideal}

Sociologists of science have typically attributed to scientific research what I call the 'traditional service ideal': the disinterested search for truth. I take the latter phrase from Wilensky, who wrote in his landmark 1964 paper:

... the scientist's disinterested search for truth is the functional equivalent of the professional's technical service ideal... (Wilensky 1964, p. 141).

Other sociologists have subscribed to this view of the scientific service ideal, most notably Merton (Merton 1942) who ascribes four values to the scientific ethos: universalism, communism, disinterestedness, and organized skepticism. While he does not use the exact phrase "the disinterested search for truth," by "disinterestedness" Merton is referring to the same ideal (see Merton 1942, pp. 124-125): scientists should not be influenced by considerations of personal gain, nor by societal pressure, but only by a motivation to pursue knowledge or objective truth in a disinterested way. 
Note that a service ideal may not be a factually accurate description of the motivations of many scientists at any given time (who may have stronger motivations to acquire recognition from their peers, or to advance their careers). The service ideal concerns ethical principle, rather than ethical practice. Further, it may not be desirable that all scientists would consciously embark on a purely disinterested search for truth, since individual scientists are not always the best judge of what research activities will advance scientific inquiry as a whole (Kitcher 1990). Thus, philosophers such as Kitcher would argue that, in the interests of scientific progress, limits should be placed on the autonomy of individual scientists to choose their research topics.

Such considerations raise the question of what mix of logics is optimal for scientific research (see final section). Nonetheless, it should be noted the service ideal is a norm both at the individual level and at the community level. In particular, the impact of the service ideal also includes the effects on the policy-makers who determine the incentives for individual scientists (in professionalism, there is also autonomy at the group-level). Thus while individuals may not consciously follow a social norm, their actions may nonetheless be largely shaped by it (see Bicchieri 2016). ${ }^{11}$ By contrast, in the complete absence of any service ideal - and the concomitant destruction of the logic of professionalism - the Freidsonian framework predicts that trust in scientists would then diminish, leading to greater external control, either through a logic of marketization, or a logic of bureaucratization. In sum, the role of the service ideal goes far beyond structuring individual scientists' motivations; it also orients policy-making and institutional structures.

\section{Current Scientists' Codes of Conduct on the Service Ideal}

\footnotetext{
${ }^{11}$ See also how Merton emphasizes the institutional element in the value of disinterestedness: "It is rather a distinctive pattern of institutional control of a wide range of motives which characterizes the behavior of scientists. For once the institution enjoins disinterested activity, it is to the interest of scientists to conform on pain of sanctions and, insofar as the norm has been internalized, on pain of psychological conflict" (Merton 1942, p. 142.)
} 
Where do current codes of conduct stand today with regard to the traditional service ideal? Consider the four principles put forward by the European Code of Conduct for Research Integrity:

(1) Reliability in ensuring the quality of research, reflected in the design, the methodology, the analysis and the use of resources.

(2) Honesty in developing, undertaking, reviewing, reporting and communicating research in a transparent, fair, full and unbiased way.

(3) Respect for colleagues, research participants, society, ecosystems, cultural heritage and the environment.

(4) Accountability for the research from idea to publication, for its management and organization, for training, supervision and mentoring, and for its wider impacts (ESF-ALLEA 2017, p. 4).

The values of honesty, respect, and accountability do not correspond to the traditional service ideal. Rather, they concern what Wilensky would have categorized as auxiliary norms regarding colleague and client relations. Moreover, as values, they do not seem particularly unique to the activity of scientific research, as the same values would be applicable to a business selling a product, or to a manager responsible for the internal organization of a corporation.

Of the four principles, 'reliability' comes perhaps closest to the traditional service ideal, since one can reasonably assume that producing reliable high-quality research is the most important way to search for truth. However, it is not identical to the traditional service ideal. A scientist can conduct highly reliable research purely for reasons of career advancement; by contrast, if the same scientist were motivated by a disinterested search for truth, then he or she might choose to embark on very different research projects. Reliability is a value that can be equally compatible with scientific work that is (more) driven by market needs or bureaucratic procedures (for discussion of objectivity in industry-funded research, see K. C. Elliott 2018). Surveys of trust in science - trust being part and parcel of a logic of professionalism - seem to support this, with industry-funded research trusted less than academic research (Besley et al. 2017). In sum, it is doubtful that a value such as reliability could replace the traditional service ideal. 
A further aspect in which the principles of the European Code of Conduct diverge from a professional service ideal is that they are very much tailored to individual scientists, even though institutions and policy makers have significant impact on the direction that scientific research takes (through hiring policies, or funding decisions). By contrast, the professional service ideal is applicable not only to the activity of individual professionals, but also to the community of professionals.

[Table 1 here]

Table 1 represents a review of the service ideals in current codes of conduct for scientists (as well as important policy documents or guidelines). Among non-traditional service ideals, a further distinction has been made between methodological and social ideals. What I call methodological ideals concern the ways in which scientists structure their research activities, and are signaled by "rigor," "diligence," "reliability," "verifiability," "impartiality," and "critical questioning." The social ideals concern ideal interpersonal relations between scientists and are signaled by words such as "respect," "honesty," "transparency," "accountability," "fairness." Both methodological and social ideals are auxiliary to the traditional service ideal.

\section{Autonomy and Competence in Scientists' Codes of Conduct}

Autonomy is the second core aspect of professionalism, closely related to the service ideal. This section outlines what the relation is between autonomy, responsibility, and competence, and shows how current codes of conduct for scientists diverge from the logic of professionalism also in this second aspect.

The Relationship between Autonomy, Responsibility, and Competence. 
Recall how discretion refers to the capacity of individuals to choose an appropriate response to a challenge in their working environment. A doctor's discretion means that the doctor deliberates on the most appropriate treatment for a patient and can choose a particular course of action without seeking approval from an external committee. A lawyer's discretion entails the lawyer relying on his or her own judgment on what the best legal advice is given the particularities of the client's problem.

In the logic of professionalism, the practitioner's discretion is assumed to be directed towards the service ideal. This means that the practitioner can choose to do the work in a way that may not necessarily coincide with the preferences of the client. This directedness towards the service ideal also underlies a client's trust in a professional: a professional is given discretion because clients trust that the professional will take all the steps necessary towards the service ideal, and is in a superior position to do so because of mastery of a certain body of knowledge. Ideally, the professional will not even be swayed by political forces that may not always be aligned with the service ideal. ${ }^{12}$

All this implies that the professional assumes responsibility for the service, because the professional - and not the consumer, or a manager - is the person who decided to carry out the professional activity in one way rather than another. The professional can be held accountable for a deficient service when it should have been competent, given the knowledge the professional was expected to have. In this way, discretion and responsibility are two sides of the same coin of individual autonomy: one cannot have discretion without also having at least a considerable degree of responsibility for the outcome.

Yet 'honest errors' can also occur, despite the professional taking every precaution to live up to the service ideal, some factor outside the professional's area of control has intervened

\footnotetext{
${ }^{12}$ Even though, of course, history shows that when the political forces are powerful enough, professional service ideals are typically compromised (as happened during the Nazi era; see Brante 2011, p.7).
} 
and prevented a successful service. So, in cases where a professional service has resulted in an adverse outcome, the question often becomes important whether the professional should assume responsibility for the adverse outcome or not. This is typically done by distinguishing between different levels of intent. The Model Penal Code distinguishes between following four levels of intent:

Purpose: An act A is committed 'purposely' by a person if the act or the cause of the act is the conscious intention of the person.

Knowledge: An act A is committed 'knowingly' if the person knows and is aware that A will be a likely consequence of his or her actions - but the act is not necessarily a conscious intention in the mind of the person.

Recklessness: An act A is committed 'recklessly' if the perpetrator knows that A could occur but disregards the risk. Thus, there is knowledge, but no awareness that A would likely occur.

Negligence: Finally, an act A is committed 'negligently' when the perpetrator is ignorant that A could occur, but should have known. (Adapted from Dubber, 2015).

In this subdivision, negligence is the only level of intent where there is no conscious awareness present of the possible consequences of the action, and of the four categories it is typically judged to be the least serious offense. A typical example of negligence would be a construction company that is unaware of safety regulations: this lack of knowledge does not exculpate the company in the case of a workplace accident. Medical malpractice is another example of negligent action (Hall 2014, p. 19).

In this way, it is important to note that negligence concerns the state of the professional's knowledge. It does not concern the conscious intention, ${ }^{13}$ which may have still been directed at

\footnotetext{
${ }^{13}$ Intent can refer to the actual state of mind (subjective intent), or to what should have been the state of mind at the time the act occurred (objective intent): see Hall, 2014, p. 74.
} 
the service ideal; rather, it concerns whether the professional was in possession of the relevant or state-of-the-art professional knowledge before carrying out the activity. To formulate negligence in terms of competence: negligence arises from not possessing competence even though one should have been in possession of it. With recklessness, by contrast, the professional possesses the required competence, but actively disregards the service ideal (by e.g. cutting corners). However, negligence also violates the service ideal, either by not referring a client to a competent colleague or by not acting to obtain state-of-the-art knowledge and training.

\section{Competence in Medicine and Law}

Since obtaining and maintaining competence is a crucial part of a professional's autonomy, the statements of codes of conduct regarding competence are proxies for how they view professional autonomy. As an illustration, the very first principle in the AMA's Code of Medical Ethics concerns competence:

A physician shall be dedicated to providing competent medical care, with compassion and respect for human dignity and rights (my emphasis).

Similarly, in the code of conduct of the International Bar Association (IBA), competence is explicitly included in the code of conduct: "A lawyer's work shall be carried out in a competent and timely manner" (IBA (International Bar Association) 2011, p. 7). The inclusion of this provision of the code is emphasized later by referring to the trust of the client:

...the client is entitled to assume that the lawyer has the ability and capacity to deal adequately with all legal matters to be undertaken on the client's behalf or to procure that somebody else either in or outside the law firm will do it (IBA (International Bar Association) 2011, p. 30).

Thus, a client can presume that the lawyer providing the service is competent, for if not competent, the lawyer would have referred the client to a colleague (in the Netherlands this is even enshrined in law: consult supplementary materials). 
For the following it will be useful to distinguish between two aspects of competence. The first is the competence of the practitioner, which refers to the state of knowledge of the practitioner. The second is the competence of the service, which refers to the quality of the service carried out by a practitioner. It is possible that a practitioner, though competent in the first sense, may nonetheless provide an incompetent service, for instance if swayed by perverse incentives or due to personal difficulties.

\section{Competence in Scientific Research}

What do competence and negligence mean in the context of scientific research? Recall that there is a considerable role for individual scientists' discretion on judging hypotheses and empirical observations. Recall also that scientists have the discretion (limited, of course, by funding constraints) on whether to embark on a certain research project rather than another. In collaborations, discretion may be spread over multiple individuals. This role of discretion implies that individual scientists, as autonomous individuals, should also be held accountable for completed scientific studies that are later found to be incompetent.

Incompetent research does not include failed studies: the latter are inherent to the riskiness of the activity of research. Strictly speaking, according to the logic of professionalism, incompetent research is research that does not contribute to, or even detracts from the service ideal. It can result from outright misconduct, such as falsification, since such research feeds falsehoods to members of the scientific community. However, it can also result from a researcher's lack of knowledge of methodological standards, for instance standard statistical techniques or procedural standards (experimental procedure, data management etc.). For this latter to be considered negligent incompetence, knowledge of the methodological standards would need to be considered as a reasonable expectation. 
The category of incompetent research, from the perspective of professionalism, goes beyond research that falls short of methodological ideals. It includes research that is reliable (and methodologically competent) but done, for instance, purely in the interests of career advancement - such as republishing old research (without a genuine effort to advance that research), or choosing to research a fashionable topic purely for the sake of career advancement. Viewed in this way, providing 'competent research' is an exacting demand - one which today undoubtedly involves individual scientists having to buffer financial incentives or bureaucratic procedures.

\section{Scientists' Codes of Conduct on Competence.}

In perhaps the most important document on research integrity in the USA, the Federal Policy on Research Misconduct, it is stipulated that misconduct must be committed “intentionally, knowingly, or recklessly," thereby excluding the lowest level of intent identified in the Model Penal Code (Dubber 2015) - negligence - from the category of misconduct. Incompetent research as such (as defined above) is therefore not an infringement of the policy.

A comparable, even if somewhat less clear situation pertains in Europe. The 2017 version of the European Code of Conduct for Research Integrity defines misconduct by means of a list of offenses that are committed intentionally or knowingly. The three offenses that are counted as "direct violation" (ESF-ALLEA 2017, p. 8) are fabrication, falsification, and plagiarism. These all imply some type of conscious intent: fabrications do not happen accidentally, and it is reasonable to assume that every practicing scientist knows that fabrication is unacceptable (thus ruling out negligence). By contrast, some of the other "unacceptable practices" (ESF-ALLEA 2017, p. 8), such as misrepresenting or exaggerating the importance of research findings, could conceivably arise negligently, through lack of competence in a particular scientific domain. However, it is unclear whether negligent actions 
are in fact an infraction of the code, since it is only stated that "in their most serious form, unacceptable practices are sanctionable" (ESF-ALLEA 2017, p. 9), without specifying what 'serious' means.

Table 2 gives a more general overview of how codes of conduct for the scientific community contrast with those in the medical and legal professions in major OECD countries. Medical and legal codes of conduct, without exception, are acutely concerned with the issue of incompetent service through negligence. By contrast, the majority of the codes of conduct for scientists are silent (or ambiguous) on this matter. (For methodological detail underlying Table 2, consult supplementary materials.)

[Table 2 here]

Some disciplines (e.g. psychology) have a significant clinical or therapeutic aspect, and thus deal with clients on a regular basis. Therefore, perhaps unsurprisingly, when we look at the discipline-specific codes of conduct across a range of disciplines, we see a large variation in stances on incompetence. As Wilensky noted:

...where a scientific discipline has a substantial segment of its adherents fully engaged in applied work, the requisites of a profession are generally met (Wilensky 1964, p. 141).

Table 3 shows how incompetence is listed as a serious infraction in codes of conduct in psychology, just as it is for physicians. Sociologists also offer their services to external parties in a non-academic setting, but only in Anglo-American countries is incompetence as such listed as an infraction. Finally, in more theoretical disciplines with little if any contact with clients, such as physics and philosophy, incompetence is mentioned even less frequently, if at all.

[Table 3 here]

These differences between science and the professions, as well as between scientific disciplines raise a number of questions. Why is it that most, but not all, codes of conduct do not list negligent incompetence as an infraction? Is it that the scientific community is still finding 
its way along the professionalization curve - and are the recent codes of conduct such as those in the Netherlands and Australia an indication of a trend? Or are there good reasons for not listing negligent incompetence as an infraction?

Any potential listing of negligent incompetence would need to involve one other crucial but difficult step: specifying what the standards are that can be reasonably expected of 'professional' scientists. For some issues, such as data management or supervisory duties, it would seem to be relatively easy to specify what the expected standards are; for other issues, such as what it means to choose research projects guided by the service ideal, such specification would seem much more difficult, or even impossible.

This difficulty in pinning down what research negligence means derives directly from the broad and ill-defined nature of the traditional service ideal itself (i.e., the disinterested search for truth). While this means that the service ideal cannot be directly translated into social and legal reality, and needs to be supported by auxiliary norms or procedures, this lack of clarity is also a strength, since abstract statements on the service ideal (and corresponding notions of negligence) are attempts to appeal directly to the ethical conscience of scientists. Nonetheless, the difficulty in specifying such reasonably expected standards - as well as identifying what the proportional and productive responses to negligent incompetence could be - could be one reason why a mention of negligent incompetence has been avoided in many codes or policy documents.

In sum, the logic of professionalism implies that responsibility is taken for negligent actions. However, in most codes of conduct or guidelines on research integrity, negligent incompetence is not included as misconduct. Some more recent documents have included negligent action as a potential infringement; however, these documents do not specify what reasonable standards of competence are to be expected. Without such specifications, it remains unclear under what circumstances actions can be judged to be negligent. 


\section{Discussion: Two Directions for Research Integrity}

In this paper, codes of conduct and guidelines have been contrasted with the logic of professionalism. In this final section I want to add a final layer of complexity: these same codes and guidelines can also possibly be interpreted as strengthening the logic of bureaucracy. In the latter view, a code of conduct will be used by boards or commissions within the professional body to create additional procedures to which the professional must submit before carrying out the professional activity. Thus, a code of conduct can also function as a first step towards creating a set of rules within a bureaucratic-managerial model of regulation. In this section I will discuss this ambiguity, and will argue that this ambiguity is objective: the scientific community is at a genuine cross-roads, so to speak.

To understand this, it is instructive to look at what happened in research ethics (specifically concerned with the rights of human and animal test subjects). Developed following the atrocities committed during the Second World War in the name of science, these codes of ethics have a certain ideal in mind - namely scientific research that conforms to basic moral principles concerning human rights (later expanded to animal rights). However, these codes of ethics have not been used to further the professionalization of science, in the sense of strengthening the autonomy of individual scientists; rather, they have also been used for adding a layer of bureaucracy to research. Scientists embarking on a clinical trial cannot merely rely on their own judgment with regard to the ethical dimension of the trial; rather, they must submit a research protocol to a research ethics committee in order to gain ethical approval. The function of regulations in research ethics is to constrain rather than strengthen the autonomy of individual scientists.

The transition to a bureaucratic-managerial logic can be traced directly in the history of the codes. The Nuremberg Code (from 1947; see Shuster 1997) and the original Helsinki 
Declaration (1964) do not make any reference to ethics committees, but only to the informed consent of patients, the competence of the physician-researcher, and careful deliberation - in the words of the 1964 Helsinki Declaration, "careful assessment of inherent risks in comparison to foreseeable benefits to the subject or to others" (Principle 4). By contrast, in the first revision of the Declaration of Helsinki (WMA 1975), review by an independent committee was included as a basic principle (Principle 2), a principle that has since been expanded into a separate section (see WMA 2013).

Returning to research integrity with this in mind, it is difficult to ignore the evidence that the social structures in the scientific community have been increasingly (but to varying extents in different countries and institutions) organized according to the principles of managerial bureaucracy. Thus, some sociologists point to new governance regimes (Carvalho and Santiago 2010), while others (Dickel 2016) have pointed to the introduction of digital technologies (which democratize knowledge), as well as to the introduction of research metrics, such as the h-index, which allow non-scientists to measure scientific performance. In the view of these sociologists, scientific research is going through a partial de-professionalization, and turning into a hybrid profession.

Codes of conduct may, over time, serve to strengthen this hybridization. For instance, in "Safeguarding Good Scientific Practice" (DFG (German Research Foundation) 2013) it is stated that "Only science itself can guarantee good scientific practice, primarily with organizational and procedural regulations." While couched in self-regulatory terms ("science itself"), on a longer time-scale this could mean the creation of special administrative positions or panels dedicated to the organizational and procedural regulations on research integrity, and to ensuring that individual researchers follow these regulations. In such a scenario, a code of conduct would then have constituted a first step towards the further bureaucratization of scientific research. 
Yet, the principles of research integrity concern the very activity of scientific research, and adherence to them cannot be outsourced to an external commission, as was the case for the principles of research ethics, which concern the rights of human and animal test subjects (arguably the subject matter for ethicists, not scientists). So, the evolution of the principles of research ethics does not seem to be a model for research integrity. Nonetheless, it is eminently possible that bureaucratic control overshoots, leading to an undesirable weakening of professionalism and sub-optimal outcomes for science, as has happened before in other professions (Freidson 2001, pp. 179 ff.).

A further complicating factor here is how the mix of organization logics is also likely to be different for different scientific domains. As mentioned above, the appropriate logic depends on the nature of the knowledge upon which the activity is based, and different scientific disciplines involve knowledge with varying degrees of abstractness. For some areas, the design and execution of a study can be sharply distinguished (e.g., clinical trials); for other areas, the distinction cannot be made (e.g., philosophy, or history). Moreover, some areas of scientific inquiry involve large collaborations entailing a division of labor (e.g., compare research in pure mathematics with cancer research). The organizational division of labor for a single activity (which is different from the division of labor within a professional community) necessitates the weakening of professionalism and the institution of at least some bureaucratic control (Abbott 1988, pp. 325-326).

However, these issues are at a finer grain of analysis than the level at which this paper is to be situated, and do not detract from the overall argument, namely, that professionalism is the logic primarily applicable to science. Current codes of conduct are, in this respect, a missed opportunity to strengthen the logic or ideology of professionalism within the scientific community. According to the latter logic, codes of conduct are not means to constrain the autonomy of scientists, but, by emphasizing the service ideal, aim at enhancing their autonomy, 
which is endangered by perverse incentives and perverse competition (see also Anderson et al. 2007).

\section{Conclusion}

By drawing on the sociology of the professions, this paper has explored a novel way of investigating research integrity compared to the dominant approach within the applied ethics literature. The latter remains predominantly focused on cataloguing states of affairs, such as the frequency of misconduct (Fanelli 2009; De Vries et al. 2006), the variations in definitions of misconduct across institutions (Resnik, Neal, et al. 2015), or variations in policy across countries (Godecharle et al. 2013). The normative component of these studies typically consists in an appeal to the autonomy of individual scientists or an appeal that policy makers do better, and thus these studies largely ignore the social structures constraining the autonomy of scientists or policy makers. By contrast, by drawing on the sociology of the professions, the ethicist can map more clearly how the very nature of scientific research constrains what modes of organization of the scientific community are appropriate, and hence what normative conclusions are realistic.

The framework developed in this paper stands in contrast to many science policy suggestions, which seem to (implicitly) assume either the market or the bureaucracy model. Within the first model, the focus lies on reforming the incentives of scientists, for instance, by increasing the incentive to do replication research (IAP 2018), or by changing career incentives - i.e., the way in which hiring, promotion, and tenure decisions are made (Moher et al. 2018). In the second model, the focus lies on creating new procedures. An example of this is the proposed Registered Reports initiative (e.g. Munafò et al. 2017), where journals make a decision to publish a study based on a detailed proposed protocol, but before results are known, in order to avoid questionable practices such as HARKing (Hypothesizing After the Results are 
Known). This initiative, if it were to be widely implemented, would amount to an additional bureaucratic procedure for scientists.

By contrast, this paper provides an argument for the importance of strengthening both the professional autonomy of researchers and a service ideal. It is likely that this implicitly has been one of the core motivations for introducing scientists' codes of conduct in the first place - in this respect, the current paper provides a theoretical framework to understand why codes of conduct for scientists are in fact so important.

However, in this paper I have shown how many codes of conduct, as they currently stand, diverge from the logic of professionalism: this can be seen quite clearly by comparing scientists' codes of conduct with the codes of conduct in law or medicine, where the logic of professionalism has a much longer history than it does in scientific research. In particular, within a logic of professionalism, social and methodological ideals (such as 'respect' or 'reliability') are necessary but are not sufficient for a full service ideal, and the traditional service ideal of the disinterested search for truth should be included in any scientists' code of conduct. It is due to an adherence to these service ideals that professionals and professional communities are trusted and thus given significant autonomy in the first place. The flipside of the coin of autonomy is that individual researchers who conduct their research according to their own discretionary judgment - and not that of administrators in institutions, nor of clients in the wider society - should also be held responsible when their research falls short of the service ideal.

Whether scientists' codes of conduct will be the basis for a stronger sense of professionalism or a first step towards an increased bureaucratization remains unclear. Many codes of conduct are still very new and are likely to change substantially in the future. However, if the codes of conduct are to be the basis for a stronger professionalism, then they need to take 
a stronger stand on the issues of the autonomy of individual researchers and the service ideal of scientific research.

\section{References}

ABA, (American Bar Association). (2018). Model Rules of Professional Conduct. https://www.americanbar.org/groups/professional_responsibility/publications/mod el_rules_of_professional_conduct/. Accessed 27 January 2019

Abbott, A. (1988). The System of Professions: An Essay on the Division of Expert Labor. University of Chicago Press.

AMA, A. M. A. (2001). AMA Code of Medical Ethics. https://www.amaassn.org/sites/default/files/media-browser/principles-of-medical-ethics.pdf. Accessed 28 March 2018

Andersen, H., \& Hepburn, B. (2016). Scientific Method. In E. N. Zalta (Ed.), The Stanford Encyclopedia of Philosophy (Summer 2016.). Metaphysics Research Lab, Stanford University. https://plato.stanford.edu/archives/sum2016/entries/scientific-method/. Accessed 2 July 2019

Anderson, M. S., Ronning, E. A., De Vries, R., \& Martinson, B. C. (2007). The Perverse Effects of Competition on Scientists' Work and Relationships. Science and Engineering Ethics, 13(4), 437-461. https://doi.org/10.1007/s11948-007-9042-5

Baker, M. (2016). Is There a Reproducibility Crisis? Nature News, 533(7604), 452-454. https://doi.org/10.1038/533452a

Besley, J. C., McCright, A. M., Zahry, N. R., Elliott, K. C., Kaminski, N. E., \& Martin, J. D. (2017). Perceived conflict of interest in health science partnerships. PLOS ONE, 12(4), e0175643. https://doi.org/10.1371/journal.pone.0175643 
Bicchieri, C. (2016). Norms in the Wild: How to Diagnose, Measure, and Change Social Norms. Oxford University Press.

Bornmann, L. (2013). Research Misconduct-Definitions, Manifestations and Extent. Publications, 1(3), 87-98. https://doi.org/10.3390/publications1030087

Bouter, L. M. (2015). Commentary: Perverse Incentives or Rotten Apples? Accountability in Research, 22(3), 148-161. https://doi.org/10.1080/08989621.2014.950253

Boyce, R. A. (2008). Professionalism meets entrepreneurialism and managerialism. In E. Kuhlmann \& M. Saks (Eds.), Rethinking professional governance: International directions in healthcare. Policy Press. https://doi.org/10.1332/policypress/9781861349569.001.0001

Brante, T. (2011). Professions as Science-Based Occupations. Professions and Professionalism, 1(1). https://doi.org/10.7577/pp.v1i1.147

Bulmer, M. (2004). Did Jenkin's swamping argument invalidate Darwin's theory of natural selection? The British Journal for the History of Science, 37(3), 281-297. https://doi.org/10.1017/S0007087404005850

Carvalho, T. (2014). Changing connections between professionalism and managerialism: a case study of nursing in Portugal. Journal of Professions and Organization, 1(2), 176190. https://doi.org/10.1093/jpo/jou004

Carvalho, T. (2017). The Study of the Academic Profession - Contributions from and to the Sociology of Professions. In J. Huisman \& M. Tight (Eds.), Theory and Method in Higher Education Research (Vol. 3, pp. 59-76). Emerald Publishing Limited. https://doi.org/10.1108/S2056-375220170000003004 
Carvalho, T., \& Correia, T. (2018). Editorial: Professions and Professionalism in MarketDriven Societies. Professions and Professionalism, 8(3), e3052. https://doi.org/10.7577/pp.3052

Carvalho, T., Correia, T., \& Serra, H. (2018). Professions under suspicion: what role for professional ethics and commitment in contemporary societies?, 17.

Carvalho, T., \& Santiago, R. (2010). Still Academics After All.... Higher Education Policy, 23(3), 397-411. https://doi.org/10.1057/hep.2010.17

Clark, C. (2005). The Deprofessionalisation Thesis, Accountability and Professional Character. Social Work and Society, 3(2), 9.

Collins, H. M., \& Evans, R. (2002). The Third Wave of Science Studies: Studies of Expertise and Experience. Social Studies of Science, 32(2), 235-296.

https://doi.org/10.1177/0306312702032002003

Davis, J. K. (1991). Professions, Trades, and the Obligation to Inform. Journal of Applied Philosophy, 8(2), 167-176.

De Vries, R., Anderson, M. S., \& Martinson, B. C. (2006). Normal Misbehavior: Scientists Talk about the Ethics of Research. Journal of Empirical Research on Human Research Ethics, 1(1), 43-50. https://doi.org/10.1525/jer.2006.1.1.43

DFG (German Research Foundation). (2013). Sicherung guter wissenschaftlicher Praxis / Safeguarding Good Scientific Practice. http://www.dfg.de/download/pdf/dfg_im_profil/reden_stellungnahmen/download/ empfehlung_wiss_praxis_1310.pdf. Accessed 7 February 2019

Dickel, S. (2016). Trust in technologies? Science after de-professionalization. Journal of Science Communication, 15(05). https://doi.org/10.22323/2.15050303 
Dubber, M. D. (2015). An Introduction to the Model Penal Code (2nd ed.). Oxford, UK:

Oxford University Press.

Elliott, K. C. (2018). Addressing Industry-Funded Research with Criteria for Objectivity. Philosophy of Science, 85(5), 857-868. https://doi.org/10.1086/699718

Elliott, P. (2013). The Sociology of the Professions. Palgrave Macmillan.

Enders, J. (2007). The Academic Profession. In J. J. F. Forest \& P. G. Altbach (Eds.), International Handbook of Higher Education (pp. 5-21). Dordrecht: Springer Netherlands. https://doi.org/10.1007/978-1-4020-4012-2_2

ESF-ALLEA, (European Science Foundation and All European Academies). (2017). The European Code of Conduct for Research Integrity. http://www.allea.org/wpcontent/uploads/2017/04/ALLEA-European-Code-of-Conduct-for-Research-Integrity2017.pdf. Accessed 2 July 2018

Fanelli, D. (2009). How Many Scientists Fabricate and Falsify Research? A Systematic Review and Meta-Analysis of Survey Data. PLoS ONE, 4(5), e5738.

https://doi.org/10.1371/journal.pone.0005738

Fanelli, D. (2018). Opinion: Is science really facing a reproducibility crisis, and do we need it to? Proceedings of the National Academy of Sciences, 115(11), 2628-2631. https://doi.org/10.1073/pnas.1708272114

Feyerabend, P. (1975). Against Method. London: Humanities Press.

Forsberg, E.-M., Anthun, F. O., Bailey, S., Birchley, G., Bout, H., Casonato, C., et al. (2018). Working with Research Integrity-Guidance for Research Performing Organisations: The Bonn PRINTEGER Statement. Science and Engineering Ethics, 24(4), 1023-1034. https://doi.org/10.1007/s11948-018-0034-4 
Freidson, E. (1970). Profession of Medicine: A Study of the Sociology of Applied Knowledge. University of Chicago Press.

Freidson, E. (2001). Professionalism, the Third Logic: On the Practice of Knowledge. University of Chicago Press.

German Data Forum (Ed.). (2011). Building on Progress: Expanding the Research Infrastructure for the Social, Economic, and Behavioral Sciences. Leverkusen: Budrich UniPress.

Gieryn, T. F. (1983). Boundary-Work and the Demarcation of Science from Non-Science: Strains and Interests in Professional Ideologies of Scientists. American Sociological Review, 48(6), 781-795. https://doi.org/10.2307/2095325

Godecharle, S., Nemery, B., \& Dierickx, K. (2013). Guidance on research integrity: no union in Europe. The Lancet, 381(9872), 1097-1098. https://doi.org/10.1016/S01406736(13)60759-X

Hall, D. E. (2014). Criminal Law and Procedure. Cengage Learning.

IAP, (The Interacademy Partnership). (2018). A call for action to improve the reproducibility of biomedical research. http://www.interacademies.org/39535/Improving-thereproducibility-of-biomedical-research-a-call-for-action. Accessed 25 March 2019

IBA (International Bar Association). (2011, May 28). International Principles on Conduct for the Legal Profession.

https://www.ibanet.org/Document/Default.aspx?DocumentUid=1730FC33-6D704469-9B9D-8A12C319468C. Accessed 28 March 2018

John, L. K., Loewenstein, G., \& Prelec, D. (2012). Measuring the Prevalence of Questionable Research Practices With Incentives for Truth Telling. Psychological Science, 23(5), 524-532. https://doi.org/10.1177/0956797611430953 
Kitcher, P. (1990). The Division of Cognitive Labor. The Journal of Philosophy, 87(1), 5. https://doi.org/10.2307/2026796

Kuhlmann, E., Burau, V., Correia, T., Lewandowski, R., Lionis, C., Noordegraaf, M., \& Repullo, J. (2013). "A manager in the minds of doctors:" a comparison of new modes of control in European hospitals. BMC Health Services Research, 13(1), 246. https://doi.org/10.1186/1472-6963-13-246

Kuhn, T. S. (1962). The structure of scientific revolutions ([2d ed., enl.). Chicago: University of Chicago Press.

Lakatos, I. (1978). The Methodology of Scientific Research Programmes: Philosophical Papers. Cambridge: Cambridge University Press.

Larson, M. S. (1977). The Rise of Professionalism: A Sociological Analysis. University of California Press.

Macdonald, K. M. (1995). The Sociology of the Professions. SAGE.

Marx, K., \& Engels, F. (2018). The Communist Manifesto. Jaico Publishing House.

Merton, R. K. (1942). A note on science and democracy. J. Legal \& Pol. Soc., 1, 115.

Merton, R. K. (1973). The Sociology of Science: Theoretical and Empirical Investigations. University of Chicago Press.

Moher, D., Naudet, F., Cristea, I. A., Miedema, F., Ioannidis, J. P. A., \& Goodman, S. N. (2018). Assessing scientists for hiring, promotion, and tenure. PLoS Biology, 16(3). https://doi.org/10.1371/journal.pbio.2004089

Munafò, M. R., Nosek, B. A., Bishop, D. V. M., Button, K. S., Chambers, C. D., Percie du Sert, N., et al. (2017). A manifesto for reproducible science. Nature Human Behaviour, 1(1), 0021. https://doi.org/10.1038/s41562-016-0021 
Nature. (2018). Austrian agency shows how to tackle scientific misconduct. Nature, 561, 285. https://doi.org/10.1038/d41586-018-06733-2

Noordegraaf, M. (2015). Hybrid professionalism and beyond: (New) Forms of public professionalism in changing organizational and societal contexts. Journal of Professions and Organization, 2(2), 187-206. https://doi.org/10.1093/jpo/jov002

Open Science Collaboration. (2015). Estimating the reproducibility of psychological science. Science, 349(6251), aac4716. https://doi.org/10.1126/science.aac4716

Parsons, T. (1978). Action theory and the human condition. New York: Free Press.

Perkin, H. (1969). Key Profession: The History of the Association of University Teachers. London: Routledge.

Popper, K. (2005). The Logic of Scientific Discovery. Routledge.

Price, A. R. (2013). Research Misconduct and Its Federal Regulation: The Origin and History of the Office of Research Integrity-With Personal Views by ORI's Former Associate Director for Investigative Oversight. Accountability in Research, 20(5-6), 291-319. https://doi.org/10.1080/08989621.2013.822238

Resnik, D. B., Neal, T., Raymond, A., \& Kissling, G. E. (2015). Research misconduct definitions adopted by U.S. research institutions. Accountability in Research, 22(1), 14-21. https://doi.org/10.1080/08989621.2014.891943

Resnik, D. B., Rasmussen, L. M., \& Kissling, G. E. (2015). An International Study of Research Misconduct Policies. Accountability in research, 22(5), 249-266. https://doi.org/10.1080/08989621.2014.958218

Resnik, D. B., \& Stewart, C. N. (2012). Misconduct versus Honest Error and Scientific Disagreement. Accountability in Research, 19(1), 56-63. https://doi.org/10.1080/08989621.2012.650948 
Sabharwal, M. (2013). Comparing Research Productivity Across Disciplines and Career Stages. Journal of Comparative Policy Analysis: Research and Practice, 15(2), 141163. https://doi.org/10.1080/13876988.2013.785149

Salwén, H. (2015). The Swedish Research Council's Definition of 'Scientific Misconduct': A Critique. Science and Engineering Ethics, 21(1), 115-126. https://doi.org/10.1007/s11948-014-9523-2

Shamoo, A. E., \& Resnik, D. B. (2015). Responsible conduct of research (Third edition.). Oxford ; New York: Oxford University Press.

Shapin, S. (2008). The scientific life: a moral history of a late modern vocation. Chicago: University of Chicago Press.

Shuster, E. (1997). Fifty Years Later: The Significance of the Nuremberg Code. New England Journal of Medicine, 337(20), 1436-1440. https://doi.org/10.1056/NEJM199711133372006

Smith, A. (2008). An Inquiry into the Nature and Causes of the Wealth of Nations. University of Chicago Press.

Steneck, N. H. (2013). Global Research Integrity Training. Science, 340(6132), 552-553. https://doi.org/10.1126/science.1236373

Stichweh, R. (1997). Professions in modern society. International Review of Sociology, 7(1), 95-102. https://doi.org/10.1080/03906701.1997.9971225

Taylor, P. L. (2009). Scientific self-regulation-so good, how can it fail? Commentary on "The problems with forbidding science." Science and Engineering Ethics, 15(3), 395-406. https://doi.org/10.1007/s11948-009-9123-8

Toulmin, S. E. (1970). Does the Distinction between Normal and Revolutionary Science Hold Water? In I. Lakatos \& A. Musgrave (Eds.), Criticism and the Growth of Knowledge 
(pp. 39-48). Cambridge: Cambridge University Press.

https://doi.org/10.1017/CBO9781139171434.005

Weber, M. (1978). Economy and Society: An Outline of Interpretive Sociology. University of California Press.

Wilensky, H. L. (1964). The Professionalization of Everyone? American Journal of Sociology, 70(2), 137-158. https://doi.org/10.1086/223790

WMA, (The World Medical Association). (1975). Declaration of Helsinki.

WMA, (The World Medical Association). (2013). Declaration of Helsinki: Ethical Principles for Medical Research Involving Human Subjects. https://www.wma.net/policiespost/wma-declaration-of-helsinki-ethical-principles-for-medical-research-involvinghuman-subjects/. Accessed 28 January 2019

Figures and Tables 


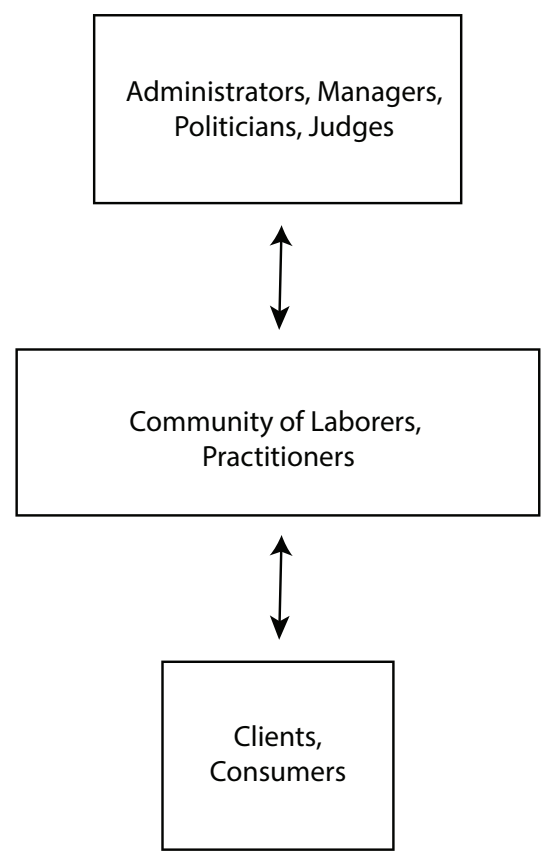

Figure 1: The organizational logic is determined by the place where autonomy is put among stakeholders

\begin{tabular}{|c|c|c|c|}
\hline $\begin{array}{ll}\text { Guideline, Policy, or Code of Conduct } & \text { Service Ideal } \\
\end{array}$ & Traditional & $\begin{array}{l}\text { Methodo- } \\
\text { logical }\end{array}$ & Social \\
\hline Federal Research Misconduct Policy (USA) & $\mathrm{N}$ & $\mathrm{N}$ & $\mathrm{N}$ \\
\hline $\begin{array}{l}\text { Fostering Integrity in Research - National Academies of } \\
\text { Sciences (USA) }\end{array}$ & $\mathrm{N}$ & $\mathrm{Y}$ & $\mathrm{Y}$ \\
\hline NRC Research Integrity Policy (CA) & $\mathrm{N}$ & $\mathrm{N}$ & Y \\
\hline Australian Code for the Responsible Conduct of Research (AU) & $\mathrm{N}$ & Y & $\mathrm{Y}$ \\
\hline The Concordat to Support Research Integrity (UK) ${ }^{14}$ & $\mathrm{~N}$ & Y & $\mathrm{Y}$ \\
\hline The European Code of Conduct for Research Integrity (Europe) & $\mathrm{N}$ & Y & Y \\
\hline Code of Ethics for Scientific Research in Belgium (BE) & $\mathrm{N}$ & Y & Y \\
\hline French national Charter for Research Integrity (FR) & $\mathrm{N}$ & Y & $\mathrm{Y}$ \\
\hline Safeguarding Good Scientific Practice (DE) & Y & Y & Y \\
\hline Guidelines for Research Integrity (IT) & $\mathrm{N}$ & Y & Y \\
\hline Netherlands Code of Conduct for Research Integrity (NL) & $\mathrm{N}$ & Y & $\mathrm{Y}$ \\
\hline
\end{tabular}

Table 1: The different service ideals present in various scientists' codes of conduct (or policy document).

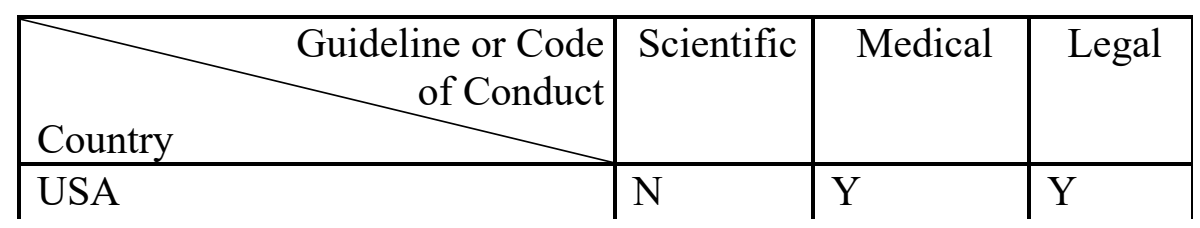

${ }^{14}$ RCUK's policy duplicates the principles of the Concordat. See supplementary materials. 


\begin{tabular}{|l|l|l|l|} 
Canada & $\mathrm{N}$ & $\mathrm{Y}$ & $\mathrm{Y}$ \\
Australia & $\mathrm{Y}$ & $\mathrm{Y}$ & $\mathrm{Y}$ \\
Europe & $\mathrm{Y} / \mathrm{N}^{15}$ & $\mathrm{Y}$ & $\mathrm{Y}$ \\
Belgium & $\mathrm{N}$ & $/$ & $\mathrm{Y}$ \\
France & $\mathrm{N}$ & $\mathrm{Y}$ & $\mathrm{Y}$ \\
Germany & $\mathrm{N}$ & $\mathrm{Y}$ & $\mathrm{Y}$ \\
Italy & $\mathrm{Y} / \mathrm{N}$ & $\mathrm{Y}$ & $\mathrm{Y}$ \\
Netherlands & $\mathrm{N}$ & $\mathrm{Y}$ & $\mathrm{Y}$ \\
\hline
\end{tabular}

Table 2: Is incompetence listed as an infringement of the code of conduct (or policy document)? Scientific versus medical and legal codes of conduct. $\mathrm{Y}=\mathrm{yes} ; \mathrm{N}=$ no; $\mathrm{Y} / \mathrm{N}=$ ambiguous; / = code not available. See supplementary materials for more details.

\begin{tabular}{|l|l|l|l|l|}
\hline $\begin{array}{r}\text { Guideline or Code } \\
\text { of Conduct }\end{array}$ & Sociology & Psychology & Physics & Philosophy \\
\hline Country & & & & \\
CSA & Y & Y & N & N \\
Australia & Y & Y & Y & N \\
UK & Y & Y & N & N \\
Europe & Y & Y & Y & N \\
Belgium & N & Y & $/$ & $/$ \\
France & $/$ & Y & $/$ & $/$ \\
Germany & $/$ & Y & $/$ & $/$ \\
Italy & N & Y & $/$ & $/$ \\
Netherlands & N & Y & $/$ & $/$ \\
\hline
\end{tabular}

Table 3: Differences between discipline-specific codes of conduct

${ }^{15}$ See supplementary materials for more detail. 